\title{
Science priorities ignore Colombia's water needs
}

\section{The government did not consult with the scientific community on reforms.}

Sir-Colciencias, the Colombian agency responsible for funding scientific research, is trying to overcome critically low investment in science and technology by establishing scientific research consortia in six strategic areas. These 'centres of research excellence' will have a budget of US $\$ 1.7$ million per centre over the next five years. The current call for proposals, which ends on 24 September, sadly ignores research related to water resources and the environment. This is a major omission, but our efforts to correct it have been in vain.

For the most part, the selected areas are relevant and genuine priorities, including biodiversity and genetic resources; infectious tropical diseases; energy development; biotechnology and food innovation. However, critical areas - most notably water and the environment - are being ignored in a country facing urgent challenges. Such omissions are made more striking by the inclusion of nanotechnology in the list of national priorities: a field unlikely to flourish here, given the lack of expertise.

Issues such as water availability and supply, water-resource management and planning, are continuing challenges in Colombia. The provision of safe drinking water is an immediate necessity for our children, dozens of whom suffer and die every day as a result of drinking polluted water. Intense tropical storms trigger flash floods and avalanches along Colombian rivers; droughts claim an even higher toll.

According to IDEAM (Colombia's public agency for hydrology, meteorology and environment), the deterioration of the Colombian environment is accelerating. The interaction between natural and social systems in the tropical Andes is one of our most urgent research challenges.

Perhaps most worrisome is the process by which the Colciencias list was drawn up. Hundreds of leading scientists and scientific institutions in Colombia, including ours, did not participate in any way in its creation. The priorities discussed in government internal documents were not circulated publicly, let alone reviewed thoroughly by the wider scientific community. It is essential that Colciencias actively involves the community in these processes, to guarantee their legitimacy and relevance for the country, in both scientific and social terms.

Germán Poveda

Graduate Programme in Water Resources, School of Geosciences and Environment, Universidad

Nacional de Colombia, Medellín, Colombia

\section{Complexity of the body calls for animal research}

Sir - The criticism of the UK animal regulatory system by Dan Lyons in Correspondence ("The animal-care regulatory system is a sham”, Nature 430, 399 ; 2004) calls for a response. Currently in my fiftieth year of pharmaceutical research, I find it depressing to realize how many legislators and citizens accept the unsupportable position of the animal activists regarding the need for animals in biomedical research.

In my lectures and writings on this subject, I emphasize the unbelievable complexity of the intact animal body. Each day, the human heart pumps some 7,200 litres of blood through the trillions of cells in the body on a continuous basis. The cells and organs share biochemical messengers every second of the day. Despite all the information published on the function of the animal body, my guess is that we know only a small percentage of the reactions going on at any moment. What conceivable system could be devised outside the intact animal that would be able to mimic the complexity of the animal body?

I agree that animals should be properly housed and maintained and suffering reduced as much as it is humanly possible to do so. Also, every surrogate test system (cell culture, enzymes, genomics, proteomics and so on), along with computers, should be and are used daily in the laboratories.

But what logical human would agree to have a new chemical, never before tested in a whole animal, administered for the first time to himself or herself?

If the animal activists prevail, new drug discovery and development will cease. This at a time when we have available to us the greatest number of disease targets in history. Why can we not get this message across to our citizens and legislators? Where is the activists' protocol for discovering a new drug without using animals? Should they not be required to detail a programme in which animals will not be used?

Charles G. Smith

USA (full address supplied)

\section{Classroom volunteers inspire young ecologists}

Sir - Your News Feature "Doing it for the kids" (Nature 430, 286-287; 2004) highlights INSPIRE, a science-education scheme in the United Kingdom where postdocs pursue a teaching qualification while continuing with their research. Although there are many positive attributes to INSPIRE, your feature acknowledges the scheme's heavy reliance on special funding, which may disappear in the future.

As noted in the News Feature, the United States currently lacks programmes equivalent to INSPIRE. But there are other US programmes that achieve many of the same goals with the help of volunteers, and without the need for additional funding. One example of this is Kids Do Ecology (KDE), an outreach programme run through the National Center for Ecological Analysis and Synthesis
(NCEAS) in Santa Barbara, California.

This programme pairs postdocs at NCEAS with classes of 10-year-olds at local schools. Each volunteer scientist visits his or her class about six times during the spring, guiding students through the scientific process by helping them develop a research question and hypothesis, design experimental methods and conduct the experiment. At the end of the semester, students from each class present their projects to other students and the NCEAS community at a poster session. A description of the experiments can be found on each class's web page, hosted through the KDE website (www.nceas. ucsb.edu/nceas-web/kids).

The benefits of KDE are many. It provides scientists with the opportunity to participate in community outreach, gives students some hands-on science experience and introduces a scientist role-model to the classroom. The programme requires a minimal time-commitment from the postdocs, about 20 hours in total on a volunteer basis, and consequently has a small budget. KDE is a sustainable model for getting scientific expertise into the classroom, and participation has remained high since its inception in 1997: 11 scientists visited classes at four Santa Barbara schools this year.

The framework for KDE is simple and effective, and could easily be adopted by other research institutions wanting to inspire student interest in science.

Sarah Abramson

National Center for Ecological Analysis and Synthesis, 735 State Street, Suite 300, Santa Barbara, California 93101, USA 